\title{
EKSTRAKSI GADOLINIUM DAN SAMARIUM DARI MINERAL MONASIT SECARA EKSTRAKSI DENGAN LIGAN ETILENDIAMINTRIMETILENFOSFONAT (EDTMP)
}

\author{
Anni Anggraeni, Titin Sofyatin, \& Husein H. Bahti \\ Departemen Kimia-Fakultas Matematika dan Ilmu pengetahuan Alam \\ Universitas Padjadjaran \\ Alamat korespondensi:
}

\begin{abstract}
Abstrak: Unsur tanah jarang yaitu gadolinium dan samarium telah banyak dimanfaatkan pada berbagai industri, bahkan bidang kedokteran. Pada penelitian ini telah dilakukan isolasi Unsur Tanah Jarang (UTJ) dari mineral monasit sebanyak $500 \mathrm{~g}$ dan mengelompokkannya berdasarkan $\mathrm{pH}$ pengendapan menjadi UTJ Berat, UTJ sedang, dan UTJ ringan, masing-masing kelompok UTJ tersebut dianalisis dengan instrumen XRF dan ICPOES. Kajian ekstraksi UTJ sedang dengan ligan EDTMP yaitu: Gd-EDTMP, Sm-EDTMP, Ce-EDTMP telah dilakukan dan efisiensi ekstraksinya di evaluasi menggunakan metode spektrofotometri sinar tampak menggunakan xylenol orange. Hasil penelitian menunjukkan bahwa pengelompokkan berhasil dilakukan secara pengendapan dengan ammonium hidroksida pada $\mathrm{pH} \mathrm{6,30-6,90} \mathrm{untuk} \mathrm{mengendapkan} \mathrm{UTJ} \mathrm{berat,} \mathrm{pH}$ 6,87,08 untuk UTJ sedang, dan $\mathrm{pH}$ 7,31-8,23 untuk UTJ ringan, Hasil analisis masing-masing kelompok UTJ menunjukkan bahwa UTJ sedang Gd, Sm, Eu, dan Tb masih terdapat pada UTJ berat dan ringan dengan kandungan yang berbeda, Rendemen kelompok berat sebanyak 98,4321 gram, kemurniannya 96,62\% dengan komposisi $\mathrm{CeO}_{2}, \mathrm{Dy}_{2} \mathrm{O}_{3}, \mathrm{Er}_{2} \mathrm{O}_{3}, \mathrm{Gd}_{2} \mathrm{O}_{3}, \mathrm{La}_{2} \mathrm{O}_{3}, \mathrm{Nd}_{2} \mathrm{O}_{3}, \mathrm{Pr}_{6} \mathrm{O}_{11}, \mathrm{Sm}_{2} \mathrm{O}_{3}, \mathrm{~Tb}_{4} \mathrm{O}_{7}$, dan $\mathrm{Y}_{2} \mathrm{O}_{3}$, UTJ sedang sebanyak 0,2035 gram, kemurniannya 93,08\% dengan komposisi $\mathrm{Ce}, \mathrm{Eu}, \mathrm{Gd}, \mathrm{La}, \mathrm{Nd}, \mathrm{Sm}$, Tb, dan $\mathrm{Y}$, dan ringan sebanyak 11,6981 gram, kemurniannya 86,95\% dengan komposisi $\mathrm{CeO}_{2}, \mathrm{La}_{2} \mathrm{O}_{3}, \mathrm{Nd}_{2} \mathrm{O}_{3}, \mathrm{Pr}_{6} \mathrm{O}_{11}, \mathrm{~Tb}_{4} \mathrm{O}_{7}$, dan $\mathrm{Y}_{2} \mathrm{O}_{3}$. Kajian ekstraksi terhadap sampel simulasi individu UTJ Gd, Sm, dan Ce melalui pembentukan kompleks dengan ligan EDTMP menunjukkan bahwa kondisi optimum ekstraksi pada pH 6 dengan efisiensi ekstraksi di atas $70 \%$. Aplikasi kondisi ekstraksi dari kajian ekstraksi sampel simulasi terhadap UTJ sedang dari monasit belum memberikan hasil yang memuaskan.
\end{abstract}

Kata kunci: Samarium, Gadolinium, EDTMP, Ekstraksi

\begin{abstract}
Rare earth elements gadolinium and samarium has been widely used in various industries, even in medicine. This study has been carried isolation Rare Earth Elements (REEs) from $500 \mathrm{~g}$ of the mineral monazite and grouping based on the $\mathrm{pH}$ of the precipitation into heavy REEs, medium REEs, and light REEs, each group REEs are analyzed by XRF instruments and ICP-OES. Studies extraction of medium REEs with ligand EDTMP namely: Gd-EDTMP, Sm-EDTMP, Ce-EDTMP has been done and the extraction efficiency was determined using visible spectrophotometry and xylenol orange. The results showed that grouping successfully done with ammonium hydroxide at a pH of 6,30 to 6,90 to precipitate the heavy REEs, $p H$ 6,8 to 7,08 for medium REEs, and a $\mathrm{pH}$ of 7,31 to 8,23 for light REEs. Results of analysis of each group REEs indicates that Gd, Sm, Eu, and $\mathrm{Tb}$ are still present in the heavy and light REEs with different composition, Rendemen heavy groups as much as 98,4321 grams, purity of 96,62\% with composition, $\mathrm{CeO}_{2}, \mathrm{Dy}_{2} \mathrm{O}_{3}, \mathrm{Er}_{2} \mathrm{O}_{3}, \mathrm{Gd}_{2} \mathrm{O}_{3}, \mathrm{La}_{2} \mathrm{O}_{3}, \mathrm{Nd}_{2} \mathrm{O}_{3}, \mathrm{Pr}_{6} \mathrm{O}_{11}, \mathrm{Sm}_{2} \mathrm{O}_{3}$, $\mathrm{Tb}_{4} \mathrm{O}_{7}$, and $\mathrm{Y}_{2} \mathrm{O}_{3}$, medium REEs as much as 0,2035 grams, purity is 93,08\% with the composition of Ce, Eu, Gd, $\mathrm{La}, \mathrm{Nd}, \mathrm{Sm}, \mathrm{Tb}$, and $\mathrm{Y}$ and light group as much as 11,6981 grams, purity of 86,95\% with a composition CeO $\mathrm{O}_{2}$, $\mathrm{La}_{2} \mathrm{O}_{3}, \mathrm{Nd}_{2} \mathrm{O}_{3}, \mathrm{Pr}_{6} \mathrm{O}_{11}, \mathrm{~Tb}_{4} \mathrm{O}_{7}$, and $\mathrm{Y}_{2} \mathrm{O}_{3}$. Extraction of the sample simulation of individual $\mathrm{REEs} \mathrm{Gd}$, $\mathrm{Sm}$, and $\mathrm{Ce}$ through the formation of complexes with ligands EDTMP showed that the optimum extraction conditions at $p H$ 6 with extraction efficiency above 70\%. Applications extraction conditions of the study to the simulated sample extraction from monazite REEs were not given satisfactory results.
\end{abstract}

Keywords : Samarium, Gadolinium, EDTMP, Extraction.

\section{PENDAHULUAN}

Unsur gadolinium dan samarium dalam bentuk kompleks

(Dietilentraminpentaasetat) sebagai senyawa pengontras pada diagnosa jaringan abnormal seperti tumor atau kanker menggunaan alat MRI (Magnetic Resonance Imaging) dan samarium-EDTMP (Etilendiamintrimetilenfosfonat) sebagai obat analgesik kuat. Unsur samarium dapat membentuk kompleks yang stabil dengan ligan EDTMP membentuk ${ }^{153} \mathrm{Sm}$-EDTMP dan merupakan radiofarmaka yang digunakan untuk terapi skeletal metastasis pada penderita kanker tulang.

Gadolinium dalam bentuk ion gadolinium (III) bersifat toksik, namun toksisitasnya dapat dikurangi setelah direaksikan dengan suatu ligan pengompleks. 
Ligan yang sering digunakan untuk membuat senyawa kompleks gadolinium (III) ialah Asam Dietiltriaminpentaasetat (DTPA) membentuk kompleks Gd-DTPA. Kompleks Gd-DTPA dapat dimanfaatkan sebagai senyawa pengontras telah terbukti aman karena memiliki kestabilan kompleks yang tinggi dan memberikan efek samping yang ringan seperti sakit kepala dan mual. Kompleks GdDTPA telah dianjurkan oleh Food and Drug Administration (FDA) USA sebagai senyawa pengontras pada tahun 1988 dengan nama dagang "Magnevist". Pada pembuatan senyawa pengontras MRI Gd-DTPA maupun Sm-EDTMP diperlukan bahan baku Gadolinium dan Samarium, yang merupakan unsur tanah jarang dari kelompok unsur tanah jarang sedang dan banyak ditemukan dalam mineral alam seperti mineral monasit. Dalam mineral monasit, gadolinium dan samarium merupakan unsur dengan komposisi yang relatif kecil sekitar 4,17\% jika dibandingkan unsur serium yang komposisi sekitar 25,03\%. Mineral monasit terdapat di beberapa wilayah Indonesia, salah satunya berasal dari hasil samping penambangan timah di P. Bangka dan Singkep. Oleh karena itu Indonesia berpotensi sebagai produsen gadolinium dan samarium untuk bahan baku pada produksi Gd-DTPA dan SmEDTMP. Menurut Fontana \& Pietrelli tahun 2009, secara konvensional unsur tanah jarang dibagi menjadi tiga kelompok:

1. Unsur tanah jarang ringan, terdiri dari lantanum (La), serium (Ce), prasedimium (Pr), ittrium $(\mathrm{Y})$ dan neodimium $(\mathrm{Nd})$.

2. Unsur tanah jarang pertengahan (sedang), terdiri dari samarium (Sm), Europium (Eu), gadolinium $(\mathrm{Gd})$ dan terbium $(\mathrm{Tb})$.

3. Unsur tanah jarang berat yang terdiri dari disprosium (Dy) sampai lutetium (Lu).

Ligan Etilendiamin tetrametilenfosfonat (EDTMP) merupakan asam fosfonat yang umumnya didapat dalam bentuk garam. EDTMP merupakan asam polifosfonat nitrogen organik. Ketahanan korosinya yaitu 3-5 jam lebih baik daripada polifosfonat anorganik, kestabilan kimianya baik, dan tahan terhadap suhu. Ini menunjukkan kemampuan tahanan yang sempurna di bawah suhu 2000C. EDTMP dapat berdisosiasi ke dalam 8 ion positifnegatif, karena itu dapat mengkhelat dengan banyak ion logam membentuk polimer kompleks. Ligan etilendiamintetrametilenfosfonat (EDTMP) merupakan senyawa dengan struktur dasar P-C-N-C$\mathrm{P}$ dan dapat membentuk senyawa kompleks yang stabil dengan berbagai radionuklida (Aziz dkk., 2010).

\section{BAHAN DAN METODE Alat-alat}

Alat-alat yang dipakai dalam penelitian ini adalah neraca analitis Mettler Toledo, pemanas listrik dan pengaduk magnet, pengayak 325 mesh, $\mathrm{pH}$ meter Mettler Toledo, tanur, termometer, oven, Inductively
Coupled Plasma - Optical Emission Spectroscopy (ICP-OES) Agilent 729, Specktrophotometer visible (Ultrospec 3000pro), autoclave, dan alat-alat gelas lain yang digunakan di laboratorium.

\section{Bahan Kimia}

Ammonium hidroksida, asam klorida, asam nitrat, asam oksalat, natrium hidroksida, samarium oksida, serium oksida, gadolinium oksida, dietil eter, etilendiamintrimetilenfosfonat, xylenol orange, asam asetat, natrium asetat. Semua bahan kimia berasal dari merck.

\section{Prosedur \\ 1. Destruksi Monasit dengan Natrium Hidroksida}

Sebanyak 500 g larutan natrium hidroksida $50 \%$ (b/b) ditambahkan ke dalam autoklaf berisi $500 \mathrm{~g}$ monasit ukuran $\leq 325$ mesh. Selanjutnya sampel dipanaskan suhu $140{ }^{\circ} \mathrm{C}$ dengan tekanan $2.5 \mathrm{~atm}$ selama 1.5 jam. Kemudian campuran didiamkan dan disaring. Endapan mengandung UTJ dan filtrat mengandung natrium fosfat, kalium fosfat dan silikat. Endapan UTJ dicuci dengan air panas sampai $\mathrm{pH}$ netral kemudian dikeringkan dalam oven pada suhu $100{ }^{\circ} \mathrm{C}$ selama 1 jam.

\section{Pemisahan Unsur Tanah Jarang(UTJ) berat, sedang dan ringan}

Endapan hasil destruksi diarutkan dalam asam klorida $37 \%$, kemudian campuran dipanaskan pada suhu $80{ }^{\circ} \mathrm{C}$ selama 1 jam. Setelah itu dilakukan pengenceran dengan penambahan akuades panas selama 1 jam pada suhu $80{ }^{\circ} \mathrm{C}$. Campuran disaring menggunakan corong Buchner. Filtrat dari pelarutan dengan asam klorida diendapkan dengan penambahan ammonium hidroksida hingga mencapai $\mathrm{pH}$ 5,8 dengan penambahan ammonium hidroksida hingga mencapai $\mathrm{pH}$ 11. Campuran disaring dan endapan unsur tanah jarang hidroksida yang diperoleh dilarutkan dengan asam nitrat $65 \%$ dan dipanaskan pada suhu $90^{\circ} \mathrm{C}$. Endapan cerium hidroksida disaring dan filtrat yang diperoleh diendapkan dengan asam oksalat. Campuran disaring dan endapan unsur tanah jarang oksalat dikeringkan dalam oven pada suhu $100^{\circ} \mathrm{C}$ selama 1 jam. Endapan UTJ oksalat dilarutkan dalam asam nitrat $65 \%$, kemudian diendapkan dengan ammonium hidroksida pada $\mathrm{pH}$ 6,30-6,90 untuk pengendapan oksida UTJ berat. Setelah itu dilakukan penyaringan. Filtrat yang diperoleh dipisahkan untuk diendapkan kembali. dengan penambahan ammonium hidroksida pada $\mathrm{pH}$ $6,82-7,08$. Filtrat yang diperoleh di endapkan kembali dengan ammonium hidroksida pada $\mathrm{pH}$ 7,31-8,23. Endapan yang diperoleh dari masing-masing $\mathrm{pH}$ pengendapan selektif dipindahkan dikalsinasi pada suhu $1000{ }^{\circ} \mathrm{C}$ selama 2 jam. Endapan oksida UTJ oksida ringan, sedang, dan berat yang diperoleh ditimbang, kemudian dilakukan analisis kandungannya dengan X-Ray Fluorescence (XRF) 
dan Inductively Coupled Plasma - Optical Emission Spectroscopy (ICP-OES) untuk mengetahui kadar oksida unsur tanah jarang berat, sedang, dan ringan yang diperoleh.

\section{Optimasi tahap ekstraksi \\ Penentuan kondisi optimum pH ekstraksi}

Sebanyak $100 \mathrm{~mL}$ larutan sampel campuran samarium, gadolinium dan serium dipipet kemudian dimasukan dalam gelas kimia dan diatur $\mathrm{pH}$ ekstraksi dengan penambahan larutan natrium hidroksida $5 \mathrm{M}$ hingga $\mathrm{pH} 5,0$. Larutan ditambahkan $20 \mathrm{~mL}$ bufer asetat $\mathrm{pH} 5,0$ sambil larutan diaduk. Kemudian ditambahkan $100 \mathrm{~mL}$ ligan EDTMP dengan perbandingan mol logam : mol ligan (1:1). Sebanyak $100 \mathrm{~mL}$ larutan dipipet dan dimasukan dalam corong pisah, lalu diekstraksi dengan $4 \times 25 \mathrm{~mL}$ dietil eter selama masing-masing 15 menit. Fasa air dan fasa organik yang terbentuk dipisahkan. Larutan sebelum ekstraksi dan fasa air diukur dengan spektrofotometer sinar tampak. Prosedur yang sama dilakukan untuk pH ekstraksi 5,5; 6; 6,5; 7 dan 7,5.

\section{Penentuan kondisi optimum ekstraksi variasi konsentrasi ligan}

Sebanyak $100 \mathrm{~mL}$ larutan sampel campuran samarium, gadolinium dan serium dipipet kemudian dimasukan dalam gelas kimia dan diatur $\mathrm{pH}$ ekstraksi dengan penambahan larutan natrium hidroksida $5 \mathrm{M}$ hingga mencapai $\mathrm{pH}$ 6,0. Larutan ditambahkan 20 $\mathrm{mL}$ bufer asetat $\mathrm{pH}$ 6,0 sambil larutan diaduk. Kemudian ditambahkan $100 \mathrm{~mL}$ ligan EDTMP dengan perbandingan mol logam : mol ligan (1:2). Sebanyak $100 \mathrm{~mL}$ larutan dipipet dan dimasukan dalam corong pisah, lalu diekstraksi dengan 4 × 25 $\mathrm{mL}$ dietil eter selama masing-masing 15 menit. Fasa air dan fasa organik yang terbentuk dipisahkan. Larutan sebelum ekstraksi dan fasa air diukur dengan spektrofotometer sinar tampak. Prosedur yang sama dilakukan untuk pH ekstraksi 6,5 dan 7,0.

\section{Optimasi tahap analisis secara spektrofotometri sinar tampak \\ Penentuan panjang gelombang serapan maksimum xylenol orange}

Larutan xylenol orange dalam bufer asetat $\mathrm{pH} 5,8$ diukur dengan menggunakan spektrofotometer sinar tampak pada panjang gelombang 400-700 $\mathrm{nm}$. Panjang gelombang yang menunjukkan absorbansi serapan maksimum dicatat sebagai panjang gelombang serapan maksimum xylenol orange.

\section{Penentuan stabilitas xylenol orange}

Larutan xylenol orange dalam bufer asetat diukur dengan menggunakan spektrofotometer sinar tampak pada panjang gelombang maksimum xylenol orange. Pengukuran dilakukan setiap 10 menit sekali dan diamati perubahan absorbansinya.

\section{Penentuan panjang gelombang serapan maksimum samarium (III), gadolinium(III) dan serium (IV)}

Larutan samarium 100 ppm ditambahkan xylenol orange dengan perbandingan 1:10, diukur dengan menggunakan spektrofotometer sinar tampak pada panjang gelombang 400-700 nm. Panjang gelombang yang menunjukkan absorbansi serapan maksimum dicatat sebagai panjang gelombang serapan maksimum xylenol orange. Prosedur yang sama dilakukan untuk larutan gadolinium dan serium.

Penentuan stabilitas kompleks samarium-xylenol orange, gadolinium-xylenol orange dan seriumxylenol orange

Larutan stok samarium dicampurkan dengan larutan xylenol orange dengan perbandingan logam : xylenol orange (1:10). Larutan diukur dengan menggunakan spektrofotometer sinar tampak pada panjang gelombang maksimum samarium. Pengukuran dilakukan setiap 10 menit sekali dan diamati perubahan absorbansinya. Prosedur yang sama dilakukan untuk kompleks serium-xylenol orange, gadolinium-xylenol orange dan kompleks campuran (samarium-gadolinium-serium)-xylenol orange.

\section{Pembuatan kurva baku samarium (III)}

Kurva baku samarium (III) dibuat dengan lima variasi konsentrasi: 5 ppm; 7,5 ppm; $10 \mathrm{ppm}$; 12,5 ppm dan $15 \mathrm{ppm}$. Analisis dilakukan dengan cara 0,5 $\mathrm{mL}$ samarium (III) ditambahkan dengan $5 \mathrm{~mL}$ xylenol orange $100 \mathrm{ppm}$ (samarium (III) : $\mathrm{XO}=1: 10$ ) kemudian masing-masing larutan dimasukan dalam labu ukur $10 \mathrm{~mL}$ dan ditambahkan akuades hingga tanda batas. Larutan dikocok selama 2 menit dan didiamkan selama 3 menit. Larutan diukur dengan spektrofotometer sinar tampak pada panjang gelombang serapan maksimum samarium. Dari data yang diperoleh, dibuat kurva kalibrasi samarium (III) yang menyatakan hubungan antara absorbansi dengan konsentrasi samarium (III). Prosedur yang sama dilakukan pada penentuan kurva baku gadolinium(III) dan serium(III).

\section{HASIL DANPEMBAHASAN}

Penelitian ini diawali dengan melakukan analisis kandungan mineral dalam sampel mineral monasit ukuran 325 mesh sebelum destruksi dengan menggunakan X-Ray Fluoresence (XRF) untuk mengetahui komposisi dari monasit tersebut. Analisis kandungan awal monasit perlu dilakukan untuk mengetahui komposisi dan persen kandungan komposisi awal dari setiap matrik yang terdapat dalam sampel monasit. Tujuannya adalah sebagai perbandingan terhadap hasil pemisahan dengan harapan komposisi UTJ semakin meningkat sedangkan komposisi non-UTJ menurun. Hasil analisis mineral awal monasit dapat dilihat pada Tabel 1. 
Destruksi monasit dilakukan menggunakan autoclaf bertekanan, agar pemanasan lebih tinggi dan proses destruksi lebih sempurna dibandingkan dengan destruksi secara terbuka. Destruksi unsur tanah jarang menurut penelitian Soe et al (2008) dilakukan dengan menggunakan larutan natrium hidroksida $50 \%$, perbandingan berat monasit dengan natrium hidroksida adalah 1:2,5. Monasit ditambahkan ke dalam larutan natrium hidroksida $50 \%$. Kemudian larutan dipanaskan pada suhu $140^{\circ} \mathrm{C}$ selama 3 jam. Pembentukan UTJ hidroksida dari hasil destruksi, Berat UTJ hidroksida yang didapat sebanyak 347 gram dari 500 gram.

UTJ hidroksida dibentuk menjadi UTJ oksida, selanjutnya UTJ oksida dipisahkan menjadi kelompok UTJ oksida berat, sedang, dan ringan melalui pengendapan dengan ammonium hidroksida, seperti pada gambar 1 .

Pada Tabel 1, tabel 2 dan Tabel 3. UTJ oksida dapat dipisahkan menjadi kelompok UTJ berat, sdang dan ringan, tetapi pada UTJ berat dan ringan masih terdapat UTJ sedang, pemisahan kelompok ini sulit dilakukan disebabkan karena sifat kimia dan valensi yang sama dari masing-masing UTJ

Untuk mengetahui efisiensi ekstraksi UTJ oleh ligan pengekstrak EDTMP diperlukan validasi pengukuran ion UTJ bebas pada fasa air, yaitu ion UTJ yang tidak terkomplekskan dengan ligan EDTMP. Pengukuran ion UTJ bebas dilakukan dengan mengunakan sepektrofotometer sinar tampak menggunakan pengompleks xylenol orange. Untuk tujuan ini diperlukan akurasi pengukuran ion UTJ bebas dalam fasa air untuk menentukan efisiensi ekstraksi. Hasil percobaan tersebut adalah sebagai berikut: Penentuan panjang gelombang serapan maksimum xylenol orange seperti pada Gambar 2. Pengukuran stabilitas xylenol orange pada suhu 25 ${ }^{\circ} \mathrm{C}$ dapat dilihat pada Gambar 3. Spektrum Smxylenol orange pada panjang gelombang sinar tampak seperti pada gambar 4. Spektrum Sm-Xylenol orange pada berbagai konsentrasi ion $\mathrm{Sm}(\mathrm{III})$ dapat dilihat pada Gambar 5.

Tabel 1. Hasil analisis mineral awal monasit sebelum destruksi dengan alat XRF

\begin{tabular}{cccc}
\hline Senyawa & Konsentrasi (\%) & $\mathrm{Senyawa}_{2}$ & Konsentrasi (\%) \\
\hline $\mathrm{CeO}_{2}$ & 31,74 & $\mathrm{Sm}_{2} \mathrm{O}_{3}$ & 1,79 \\
$\mathrm{P}_{2} \mathrm{O}_{5}$ & 23,12 & $\mathrm{SO}_{3}$ & 0,0140 \\
$\mathrm{SnO}_{2}$ & 0,331 & $\mathrm{Dy}_{2} \mathrm{O}_{3}$ & 0,395 \\
$\mathrm{Y}_{2} \mathrm{O}_{3}$ & 1,36 & $\mathrm{U}_{3} \mathrm{O}_{8}$ & 0,157 \\
$\mathrm{La}_{2} \mathrm{O}_{3}$ & 12,93 & $\mathrm{Na}_{2} \mathrm{O}$ & 0,121 \\
$\mathrm{Nd}_{2} \mathrm{O}_{3}$ & 11,88 & $\mathrm{CuO}$ & 0,157 \\
$\mathrm{TiO}_{2}$ & 0,735 & $\mathrm{ZrO}_{2}$ & 0,468 \\
$\mathrm{Fe}_{2} \mathrm{O}_{3}$ & 0,451 & $\mathrm{Er}_{2} \mathrm{O}_{3}$ & 0,0698 \\
$\mathrm{ThO}_{2}$ & 6,63 & $\mathrm{CaO}_{2}$ & 0,168 \\
$\mathrm{SiO}_{2}$ & 2,03 & $\mathrm{Al}_{2} \mathrm{O}_{3}$ & 0,600 \\
$\mathrm{Pr}_{6} \mathrm{O}_{11}$ & 2,96 & $\mathrm{PbO}$ & 0,0307 \\
$\mathrm{Gd}_{2} \mathrm{O}_{3}$ & 1,27 & $\mathrm{Eu}_{2} \mathrm{O}_{3}$ & 0,090 \\
$\mathrm{Cl}$ & 0,0107 & $\mathrm{~Tb}_{4} \mathrm{O}_{7}$ & 0.0946
\end{tabular}

Tabel 2. Hasil analisis UTJ oksida berat menggunakan instrumen XRF

\begin{tabular}{cccc}
\hline Senyawa & Konsentrasi $(\%)$ & Senyawa & Konsentrasi (\%) \\
\hline $\mathrm{Al}_{2} \mathrm{O}_{3}$ & 0,2030 & $\mathrm{Nd}_{2} \mathrm{O}_{3}$ & 15,8 \\
$\mathrm{Fe}_{2} \mathrm{O}_{3}$ & 0,0257 & $\mathrm{~Tb}_{4} \mathrm{O}_{7}$ & 0,0472 \\
$\mathrm{MnO}$ & 0,0551 & $\mathrm{La}_{2} \mathrm{O}_{3}$ & 16,53 \\
$\mathrm{CaO}$ & 0,0726 & $\mathrm{Dy}_{2} \mathrm{O}_{3}$ & 0,16 \\
$\mathrm{~K}_{2} \mathrm{O}$ & 0,0234 & $\mathrm{Er}_{2} \mathrm{O}_{3}$ & 0,0287 \\
$\mathrm{SO}_{3}$ & 0,0964 & $\mathrm{Sm}_{2} \mathrm{O}_{3}$ & 1,55 \\
$\mathrm{LOI}$ & 1,52 & $\mathrm{Pr}_{6} \mathrm{O}_{11}$ & 4,22 \\
$\mathrm{Cl}$ & 0,189 & $\mathrm{MoO}_{3}$ & 0,593 \\
$\mathrm{Gd}_{2} \mathrm{O}_{3}$ & 1,27 & $\mathrm{CeO}_{2}$ & 56,6 \\
$\mathrm{Y}_{2} \mathrm{O}_{3}$ & 0,985 & & \\
\hline
\end{tabular}


Tabel 3. Hasil analisis UTJ oksida sedang menggunakan instrumen ICP-OES

\begin{tabular}{cccc}
\hline Senyawa & Konsentrasi (\%) & Senyawa & Konsentrasi (\%) \\
\hline $\mathrm{Al}$ & 1,15 & $\mathrm{~K}$ & 0,829 \\
$\mathrm{As}$ & 0,6757 & $\mathrm{La}$ & 27,1959 \\
$\mathrm{Ba}$ & 0,0235 & $\mathrm{Mn}$ & 0,025 \\
$\mathrm{Co}$ & 0,0081 & $\mathrm{Nd}$ & 9,228 \\
$\mathrm{Cr}$ & 0,0509 & $\mathrm{Se}$ & 0,015 \\
$\mathrm{Cu}$ & 0,0257 & $\mathrm{Sm}$ & 0,9066 \\
$\mathrm{Eu}$ & 0,0289 & $\mathrm{~Tb}$ & 0,0257 \\
$\mathrm{Gd}$ & 1,03698 & $\mathrm{Y}$ & 0,1783 \\
& & $\mathrm{Zn}$ & 0,0669 \\
\hline
\end{tabular}

Tabel 4. Hasil analisis UTJ oksida sedang menggunakan instrumen ICP-OES

\begin{tabular}{cccc}
\hline Senyawa & Konsentrasi (\%) & Senyawa & Konsentrasi (\%) \\
\hline $\mathrm{Al}_{2} \mathrm{O}_{3}$ & 0,0549 & $\mathrm{Y}_{2} \mathrm{O}_{3}$ & 0,0323 \\
$\mathrm{Fe}_{2} \mathrm{O}_{3}$ & 0,0286 & $\mathrm{Nd}_{2} \mathrm{O}_{3}$ & 5,99 \\
$\mathrm{MnO}$ & 0,0768 & $\mathrm{~Tb}_{4} \mathrm{O}_{7}$ & 0,0682 \\
$\mathrm{CaO}$ & 0,123 & $\mathrm{La}_{2} \mathrm{O}_{3}$ & 69,14 \\
$\mathrm{~K}_{2} \mathrm{O}$ & 0,081 & $\mathrm{Sm}_{2} \mathrm{O}_{3}$ & 0,223 \\
$\mathrm{SO}_{3}$ & 0,0558 & $\mathrm{Pr}_{6} \mathrm{O}_{11}$ & 1,77 \\
$\mathrm{LOI}$ & 12,27 & $\mathrm{MoO}_{3}$ & 0,0891 \\
$\mathrm{Cs}_{2} \mathrm{O}$ & 0,067 & $\mathrm{CeO}_{2}$ & 9,71 \\
$\mathrm{Cl}$ & 0,0984 & & \\
\hline
\end{tabular}

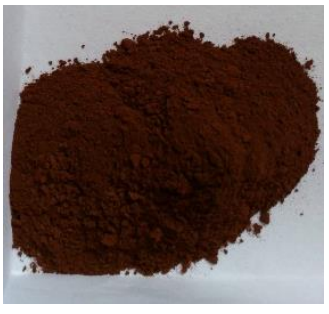

(A)

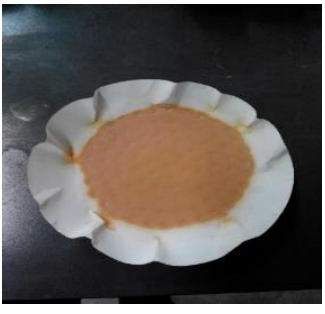

(B)

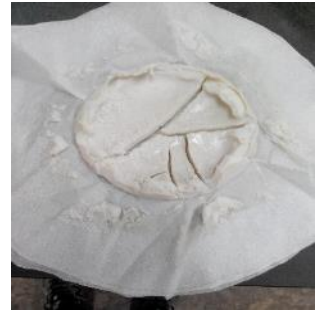

(C)

Gambar 1. UTJ Berat (A), UTJ Sedang (B), dan UTJ Ringan (C)

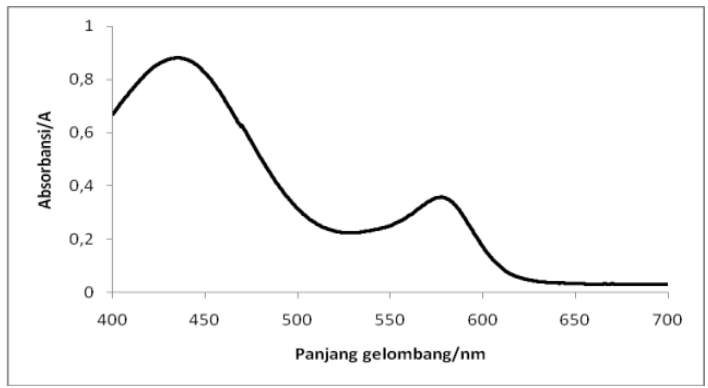

Gambar 2. $\chi$ maksimum xylenol orange

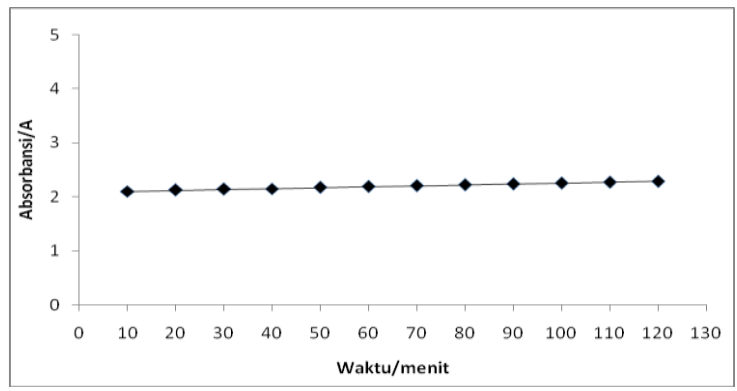

Gambar 3. Pengukuran stabilitas xylenol 


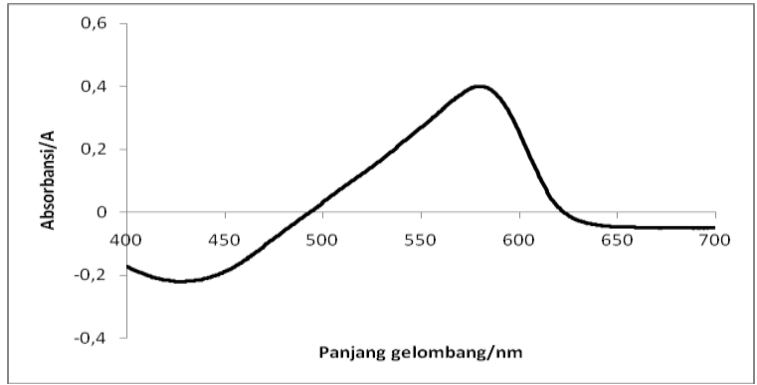

Gambar 4. Spektrum Sm-Xylenol orange

Kurva Baku Sm(III) dan Gd (III) dengan persamaan regresi linier sebelum dan sesudah pengujian intersep dapat dilihat pada Gambar 6 dan Gambar 7.

Kajian ekstraksi UTJ sedang dilakukan terhadap sampel simulasi untuk menentukan kondisi optimum ekstraksi terhadap masing-masing UTJ kelompok sedang, melalui variasi $\mathrm{pH}$ dan perbandingan mol logam: mol ligan. Hasil percobaan dapat dilihat pada Gambar 8 .

Dari Gambar 8. kondisi optimum ditunjukkan pada pH 6 dimana Gd, Ce, dan Sm terkstraksi lebih dari $70 \%$ dengan nilai KD yang berbeda.

Tabel 5. Hasil Analisis ICP-OES Fasa air setelah ekstraksi UTJ sedang dengan ligan

\begin{tabular}{cccc}
\hline Unsur & Kandungan (\%) & Unsur & Kandungan (\%) \\
\hline $\mathrm{Al}$ & 0,08 & $\mathrm{~K}$ & 0,01 \\
$\mathrm{As}$ & 0,13 & $\mathrm{La}$ & 0,00 \\
$\mathrm{Ba}$ & 0,02 & $\mathrm{Mn}$ & 0,01 \\
$\mathrm{Co}$ & 0,00 & $\mathrm{Nd}$ & 0,02 \\
$\mathrm{Cr}$ & 0,07 & $\mathrm{Se}$ & 0,009 \\
$\mathrm{Cu}$ & 0,01 & $\mathrm{Sm}$ & 0,00 \\
$\mathrm{Eu}$ & 0,00 & $\mathrm{~Tb}$ & 0,00 \\
$\mathrm{Gd}$ & 0,00 & $\mathrm{Y}$ & 0,00 \\
$\mathrm{Zn}$ & 0,00 & & \\
\hline
\end{tabular}

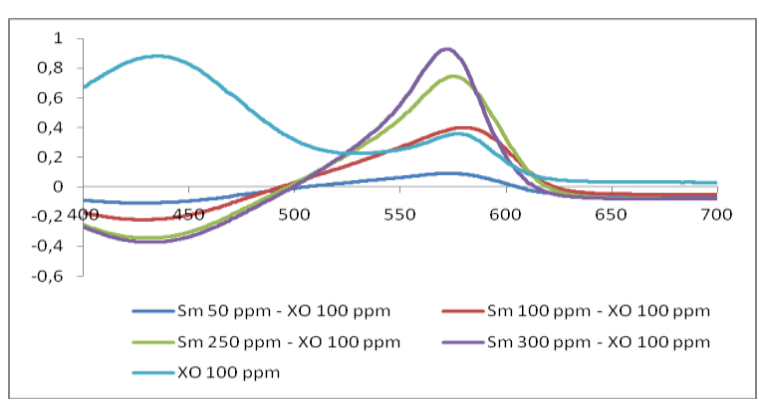

Gambar 5. Spektrum Sm-Xylenol orange pada berbagai konsentrasi $\mathrm{Sm}$

Aplikasi kondisi optimum ekstraksi terhadap ekstraksi UTJ sedang tidak memberikan hasil yang memuaskan, terlihat dari fasa air yang dianalisis setelah ekstraksi hampir semua UTJ pada kelompok sedang terekstraksi oleh ligan EDTMP yang ditunjukkan pada Tabel 5, hal ini kemungkinan disebabkan karena sifat fisik dan kimia dari masingmasing UTJ oksida kelompok sedang tersebut yang hampir sama satu dengan lainnya.

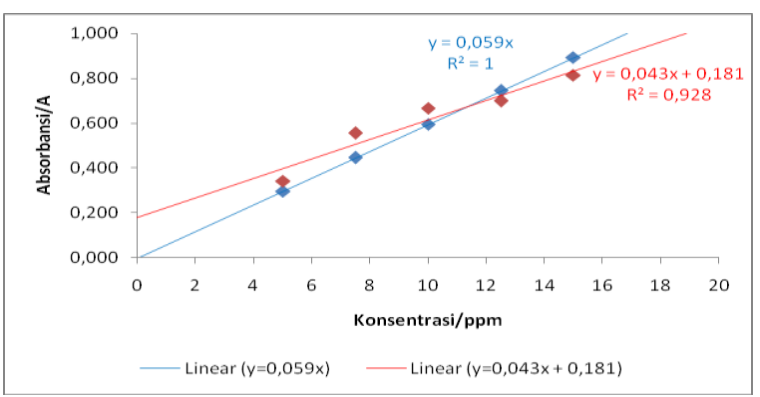

Gambar 6. Kurva baku Sm(III)

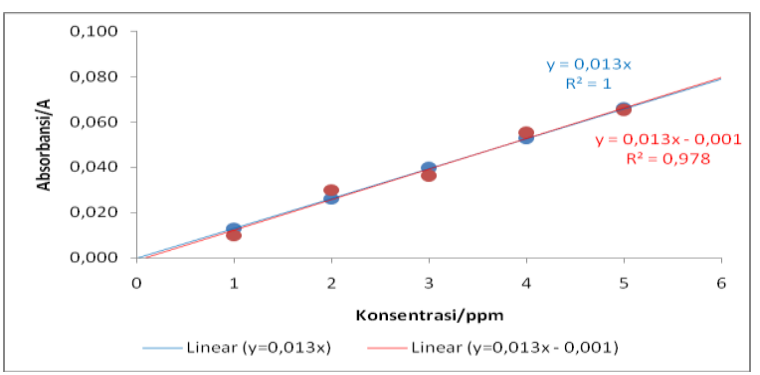

Gambar 7. Kurva baku Gd(III)

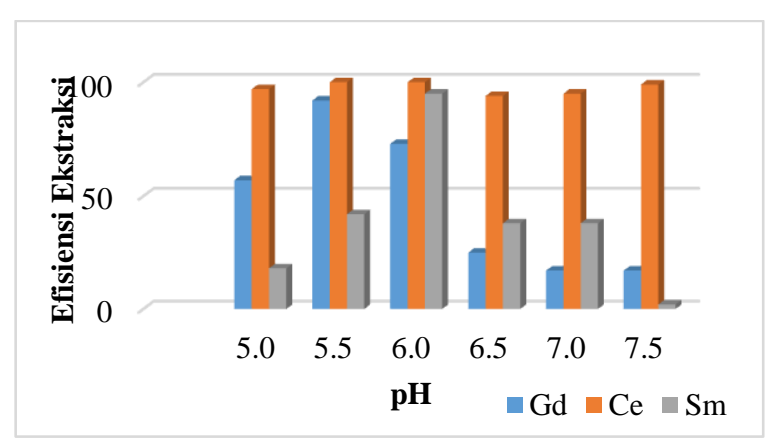

Gambar 8. Ekstraksi Gd, Ce, Sm dengan ligan pengestrak EDTMP pada variasi $\mathrm{pH}$

\section{KESIMPULAN}

Kesimpulan dari hasil penelitian adalah sebagai berikut: Pemisahan UTJ oksida menjadi UTJ oksida kelompok berat, UTJ oksida kelompok sedang, dan UTJ kelompok ringan berhasil dipisahkan tetapi belum sempurna dengan rendemen dari $500 \mathrm{~g}$ sampel monasit: UTJ oksida berat 98,4321 g , UTJ oksida sedang 0,2035 g, dan UTJ oksida ringan 11,6981 UTJ. Isolasi gadolinium dari UTJ oksida kelompok sedang menggunakan ligan EDTMP belum memberikan hasil yang memuaskan, ligan EDTMP kurang selektif terhadap gadolinium

\section{UCAPAN TERIMA KASIH}

Terimakasih kepada Direktur Penelitian dan Pengabdian Kepada Masyarakat Ditjen Dikti Kemendiknas, atas pendanaan penelitian, dan semua 
pihak yang telah membantu penelitian ini baik secara personal maupun institusi.

\section{DAFTAR PUSTAKA}

Aziz,A. Marlina \& Muhamad,B.F. 2010. Penentuan Kondisi Optimum Dalam Penandaan Ligan EDTMP dengan Radioisotop 170Tm. Iptek Nuklir Ganendra 14:19-27.

Barge, A., G. Cravotto., E. Gianolio \& F. Fedeli. 2006. How to Determine Free Gd and Free Ligand in Solution of Gd Chelates : a Technical Note. Contrast Media \& Molecular Imaging, I : $184-188$.

Bunzli, J. C. 2011. 4f element: The Element, Discovery, Properties, and Uses. Melalui http://www.scgc.epfl.ch/load/cours_chem/jbc_el 4f_chap1-1.pdf.

Deng,H. Tianzhi,T. Shuenzhong, L \& Changlin, H. 2002. Radiopharmaceutical (Sm-153-EDTMP) Therapy of Skeletal Metastases: Clinical Aplication in 350 Patients. Journal of Radiology. Melalui http://www.radiology.org

Fontana, D \& Loris, F. 2009. Separation of Middle Rare Earths by Solvent Extraction Using 2ethylheksylphosphonic acid mono-2-ethylheksyl ester. Journal of Rare Earth. 27: 830-833.

Hastini, S. Sudarsih. Robert, D.H \& Suharmadi. 2011. Pembuatan 153Samarium-EDTMP Untuk Terapi Kanker Tulang Metastasis. Seminar Penelitian \& Pengolahan Perangkat Nuklir. ISSN 1410-8178.

Morais, C. A., \& V. S. T. Ciminelli. 2004. Process development for the recovery of high-grade lanthanum by solvent extraction. Hydrometallurgy. 73: 237-244.

Purwani, M.V., Suyanti dan Muhadi,A.W.2008. Ekstraksi Konsentrat Neodimium Memakai Asam Di-2-Etil-Heksil Fosfat. Seminar nasional IV SDM Teknologi Nuklir. Yogyakarta.

Rabie, K.A. 2006 A Group Separation and Purification of Sm, Eu and Gd from Egyptian Beach Monazite Mineral Using Solvent Extraction. Hydrometallurgy 85: 81-86.

Soe, N. N., L. T. Shwe \& K. T. Lwin. 2008. Study on extraction of lanthanum oxide from monazite concentrate. World Academy of Science, Engineering and Technology. 46: 142-145.

Thomsen,V \& D. Schatzlein. 2003. The X-Ray Spektrum of Monazite. Spectroscopy,18(7), 1821. 